\title{
Identification of a gene encoding adaptin-like protein in the Paracoccidioides brasiliensis genome by random amplified polymorphic DNA analysis
}

\begin{abstract}
Correspondence
Maria José Soares Mendes-

Giannini

giannini@fcfar.unesp.br
\end{abstract}

Received 18 December 2006

Accepted 8 March 2007

\author{
Patrícia Ferrari Andreotti, ${ }^{1}$ Juliana Leal Monteiro da Silva, ${ }^{1}$ \\ Elaine Cristina Teixeira, ${ }^{2}$ Maria Célia Bertolini, ${ }^{2}$ Christiane Pienna Soares, ${ }^{1}$ \\ Gil Benard $^{3}$ and Maria José Soares Mendes-Giannini ${ }^{1}$
${ }^{1}$ Departamento de Análises Clínicas, Faculdade de Ciências Farmacêuticas, UNESP, Araraquara, SP, Brazil
${ }^{2}$ Departamento de Bioquímica e Tecnologia Química, Instituto de Química, UNESP, Araraquara, SP, Brazil
${ }^{3}$ Laboratório de Dermatologia e Imunodeficiências, Departamento de Dermatologia, Faculdade de Medicina, Universidade de São Paulo, Brazil

\begin{abstract}
Paracoccidioides brasiliensis isolates are not homogeneous in their patterns of pathogenicity in animals and adhesion to epithelial cells. During this investigation, genotypic differences were observed between two samples of $P$. brasiliensis strain 18 yeast phase ( $\mathrm{Pb} 18)$ previously cultured many times, one taken before $(\mathrm{Pb} 18 \mathrm{a})$ and the other after $(\mathrm{Pb} 18 \mathrm{~b})$ animal inoculation. Random amplified polymorphic DNA analysis using the primer OPJ4 distinguished Pb18b from $\mathrm{Pb} 18 \mathrm{a}$ by one $308 \mathrm{bp}$ DNA fragment, which after cloning and sequencing was shown to encode a polypeptide sequence homologous to the protein $\beta$-adaptin. It is suggested, by comparison to other micro-organisms, that this protein might play an important role in the virulence of $P$. brasiliensis. This result demonstrates the influence of in vitro subculturing on the genotype of this organism.
\end{abstract}

\section{INTRODUCTION}

The virulence of Paracoccidioides brasiliensis can be attenuated or lost during consecutive cycles of subculturing over long periods (Brummer et al., 1990), but re-established after inoculating into animals (Castaneda et al., 1987). Newly isolated samples of $P$. brasiliensis strain 18 (Pb18), either from infected animals or from cell cultures, recovered the capacity to adhere to and to invade epithelial cells (Andreotti et al., 2005).

Molecular biology techniques are a powerful tool to explore the diversity of pathogen strains. Random primers have been refined so that they can be used to distinguish and characterize genetic diversity among isolates of $P$. brasiliensis (Molinari-Madlum et al., 1999; Soares et al., 1995; Motta et al., 2002) and could differentiate the fungus based on virulence (Kurokawa et al., 2005).

Several coat proteins, such as heterotetrameric adaptor protein (AP) complexes, have been described that are

Abbreviation: RAPD, random amplified polymorphic DNA.

The GenBank/EMBL/DDBJ accession no. for the adaptin-like protein sequence of Paracoccidioides brasiliensis is AY675222. involved in the formation of carrier vesicles and consist of two large adaptins $(\gamma$ and $\alpha$ are found together with $\beta 1$ and $\beta 2)$, one medium-sized adaptin ( $\mu 1$ or $\mu 2)$ and one small adaptin $(\sigma 1$ or $\sigma 2)$ (Boehm \& Bonifacino, 2001).

The aim of this study was to demonstrate differences in the random amplified polymorphic DNA (RAPD) profiles of two samples of $\mathrm{Pb} 18$, one subcultured in vitro 72 times and the other recently recovered from an inoculated animal. A polymorphic DNA band that was found in the sample recovered from an inoculated animal was cloned and sequenced. The DNA fragment was part of a gene encoding an adaptin-like protein.

\section{METHODS}

Pb18 was obtained from a patient with paracoccidioidomycosis and maintained at Faculdade de Medicina, Universidade de São Paulo. During the current work, $P$. brasiliensis was cultivated in solid YEPD medium ( $2 \%$ peptone, $1 \%$ yeast extract, $2 \%$ glucose $)$ at $35{ }^{\circ} \mathrm{C}$ and subcultured 72 times, for 3-4 days each, to produce the $\mathrm{Pb} 18 \mathrm{a}$ sample. The Pb18b sample was obtained after inoculation into hamster by an intratesticular route as described by Andreotti et al. (2005). 
The Pb18a and Pb18b samples were cultivated in YEPD broth at $35^{\circ} \mathrm{C}$, overnight, under agitation, and DNA extraction for both samples was carried out based on the method of Lasker et al. (1992). The DNA was resuspended and stored in TE buffer ( $40 \mathrm{mM}$ Tris, $2 \mathrm{mM}$ EDTA) at $-20{ }^{\circ} \mathrm{C}$.

The molecular typing of the samples was carried out by RAPD-PCR, using the Ready-To-Go/RAPD analysis beads kit (GE Healthcare). For PCR amplification of the two DNA samples, the following six primers from the kit were used: 1 (5'-GGTGCGGGAA-3'), 2 ( $5^{\prime}$ GTTTCGCTCC-3'), 3 (5'-GTAGACCCGT-3'), 4 (5'-AAGAGCCCGT- $\left.3^{\prime}\right), 5$ (5'-AACGCGCAAC- $\left.3^{\prime}\right), 6$ (5'-CCCGTCAGCA- $\left.3^{\prime}\right)$. The PCR amplification products were separated by electrophoresis in a $2 \%$ agarose gel in TBE buffer and visualized with ethidium bromide.

The DNA fragment (approximately $300 \mathrm{bp}$ ) amplified by RAPD-PCR with primer 4 was removed from the agarose gel and purified with a S.N.A.P. gel purification kit (Invitrogen). The purified DNA fragment was cloned into vector pMOS (GE Healthcare) according to the manufacturer's instructions and amplified in Escherichia coli strain DH10B. For DNA sequencing, plasmids were extracted from overnight cultures and sequenced, on both strands, using the BigDye terminator cycle sequencing ready reaction kit (Applied Biosystems), and the universal T7 and U-19 primers, in an automatic DNA sequencer (ABI 377; Perkin Elmer). The nucleotide sequence of the fragment (308 bp) was translated by the Gene Runner program, analysed by BLAST at the National Center for Biotechnology Information (www.ncbi.nlm.nih.gov) and Broad Institute (www. broad.mit.edu/annotation/fgi) databases, and the protein sequence alignment performed by ClustalX program.

Approximately $30 \mu \mathrm{g}$ genomic DNA was digested with the restriction enzymes SalI, EcoRI and NdeI, electrophoresed on a $0.8 \%$ agarose gel and transferred to nylon membrane (GE Healthcare). The blot was probed with the $308 \mathrm{bp}$ DNA fragment labelled with fluorescein using the Gene Images random prime labelling module kit (GE Healthcare) and the results revealed with the Gene Images CDP-Star detection module kit (GE Healthcare) according to the manufacturer's instructions.

\section{RESULTS AND DISCUSSION}

In our study we have evaluated two samples of $P$. brasiliensis strain 18, correlating their virulence with RAPD profiles. RAPD-PCR was used for the PCR amplification and no differences in the band profiles between the two DNA samples were observed using the primers $1,2,3,5$ and 6 . However, primer 4 was able to differentiate Pb18b from Pb18a samples by one band of approximately $300 \mathrm{bp}$ that was visualized in the $\mathrm{Pb} 18 \mathrm{~b}$ DNA sample (Fig. 1). The RAPD profile was related to the $P$. brasiliensis sample presenting a high epithelial adhesion pattern (Andreotti et al., 2005). This result contrasts with the data of Motta et al. (2002), which showed that different samples of $P$. brasiliensis were not homogeneous in their ability to infect mice, but had identical RAPD profiles, showing $100 \%$ similarity between their genotypes. Calcagno et al. (1998) demonstrated that genetic variations could be associated with geographical regions but not with different clinical manifestations of paracoccidioidomycosis. However, Molinari-Madlum et al. (1999) showed that RAPD profiles could be correlated with the degree of virulence of the $P$. brasiliensis isolates. Our results support

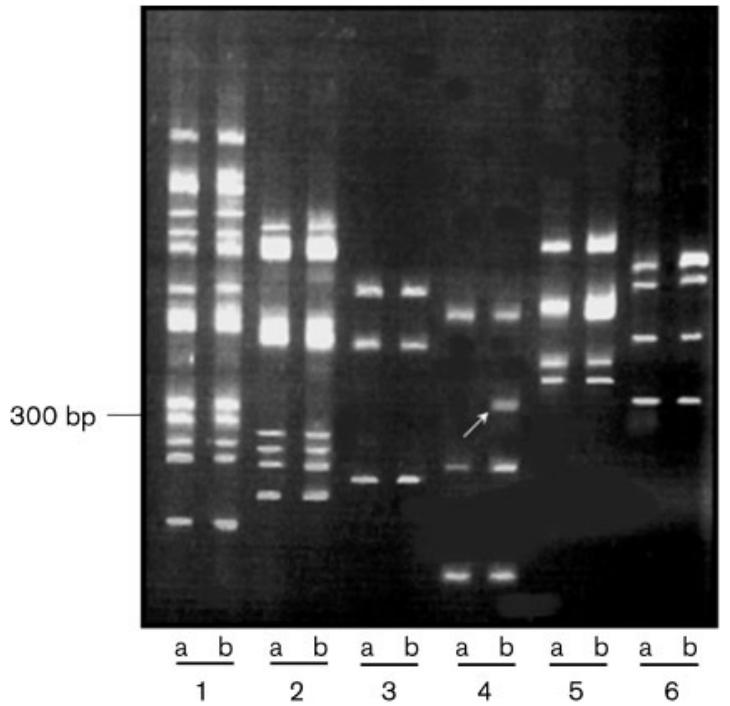

Fig. 1. RAPD-PCR analysis of $P$. brasiliensis 18 (a) before and (b) after animal inoculation. 1, 2, 3, 4, 5, 6 indicate the primers used from the Ready-To-Go/RAPD analysis beads kit (GE Healthcare). The DNA molecular mass marker is indicated on the left. The arrow indicates the polymorphic band of $308 \mathrm{bp}$.

the hypothesis that there is an influence of in vitro subculturing on the genotype of $P$. brasiliensis.

During this investigation, a 308 bp polymorphic band from genomic DNA of $P$. brasiliensis with high virulence was sequenced on both strands, and the nucleotide sequence was translated by Gene Runner program. One putative intron (66 bp) was identified in the nucleotide sequence, showing the consensus $5^{\prime}$ splice-donor site (GT) and the consensus 3' splice-acceptor site (AG) for splice donors and acceptors (Fig. 2a). The polypeptide sequence deduced from the nucleotide sequence (308 bp) was analysed by BLAST. It encodes a polypeptide homologous to proteins from the adaptin family from Aspergillus terreus (GenBank accession no. XM_001213650), Aspergillus fumigatus (GenBank accession no. XM_750274), Histoplasma capsulatum (Broad Institute accession no. HCAG_08087.1) and Aspergillus nidulans (Broad Institute accession no. AN5950.3). The polypeptide sequence corresponds to part of the N-terminal region of the protein. We classified the DNA as a sequence encoding $P$. brasiliensis adaptin-like protein and it was deposited in GenBank under the accession no. AY675222 (Fig. 2b). Four AP complexes, named AP-1, AP-2, AP-3 and AP-4, have been described in eukaryotic organisms. Biochemical and morphological evidence indicates that AP complexes play a role in the formation of vesicular transport intermediates and in the selection of cargo molecules for inclusion into these intermediates (Boehm \& Bonifacino, 2001).

The role of the adaptins in pathogenic fungus has not been studied so far. In Saccharomyces cerevisiae, the complex AP2 is not essential for endocytosis or cellular viability 
(a)

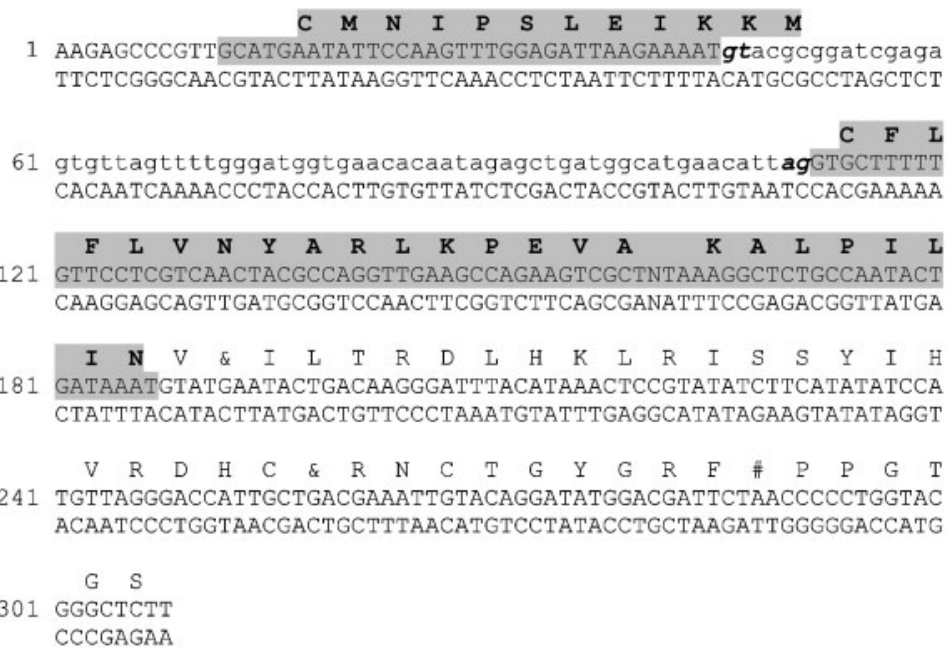

(b)
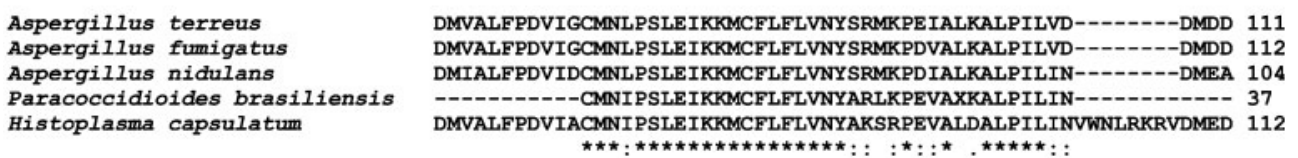

Histoplasma capsulatum

Fig. 2. (a) Nucleotide sequence of the $308 \mathrm{bp}$ fragment, translated to amino acid sequence by the Gene Runner program. The putative intron is represented in lower case and the coding region showing homology to adaptin protein family is represented by grey boxes The GT/AG rule sequences for dinucleotide donors and acceptors of splicing are represented in bold italics. (b) Sequence alignment of the translated sequence from P. brasiliensis (GenBank accession no. AY675222) with sequences of adaptin protein from $A$. terreus (GenBank accession no. XM_001213650), A. fumigatus (GenBank accession no. XM_750274), H. capsulatum (Broad Institute accession no. HCAG_08087.1) and A. nidulans (Broad Institute accession no. AN5950.3) using the ClustalX program.

(Munn, 2001). On the other hand, AP-1 complex seems to be involved with reproduction in this yeast (Boehm \& Bonifacino, 2001). In a recent study, it was demonstrated that the vesicular traffic mediated by adaptins is essential for the survival of Leishmania spp. inside of macrophages, thus playing a role in the pathogenicity of this parasite (Gokool, 2003). In Trypanosoma cruzi, AP complexes are essential for an intracellular parasite that can inhabit a range of host cell types, an adaptation that requires modulation of parasite surface molecules and active escape from the parasitophorous vacuole into the cytoplasm (Tan \& Andrews, 2002).

In this work, we isolated a DNA fragment from $P$. brasiliensis encoding a polypeptide sequence homologous to the adaptin protein family, demonstrating for what is believed to be the first time the presence of this sort of protein in the genome of this fungus. We suggest, by comparison to other micro-organisms, that this protein might play an important role in $P$. brasiliensis virulence. The sequence was only present in the $\mathrm{Pb} 18 \mathrm{~b}$ sample with a high adhesion capacity in epithelial cells and isolated from an animal, as confirmed by Southern blotting (Fig. 3), suggesting the occurrence of genetic changes. This can be explained by the $P$. brasiliensis genome being rich in transposons, in fact eight different groups of retrotransposons were identified in the transcriptome of $P$. brasiliensis, including Ty-like elements, one of the most abundant expressed sequence tags, described by Felipe et al. (2003). Recombination events involving dispersive Ty sequences can lead to inversions, deletions and translocations, which may account for the chromosomal polymorphism observed in different strains of $P$. brasiliensis (Oliveira et al., 2002), as described in this work. The mechanism causing the

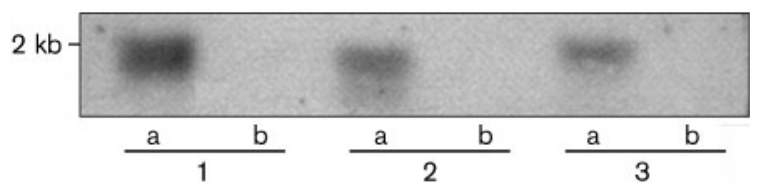

Fig. 3. Southern blotting of genomic DNA from two samples of $P$. brasiliensis, after (a) and before (b) reisolation from an animal. Approximately $30 \mu \mathrm{g}$ genomic DNA was digested with the restriction enzymes Sall (1), Ndel (2) and EcoRI (3), and electrophoresed on a $0.8 \%$ agarose gel. After electrophoresis the DNA was transferred to nylon membrane and probed with the 308 bp DNA fragment labelled with fluorescein. 
genetic diversity between both samples is still unclear, but it is possible that the fungal population changes and adapts in order to escape pressure or eradication by the immune system, as demonstrated in Cryptococcus neoformans by Fusco-Almeida et al. (2007).

\section{ACKNOWLEDGEMENTS}

The technical assistance of Julhiany de Fátima da Silva, Lilian Cristiane Baeza, Clayton Luiz Borges and Célia Maria de Almeida Soares is gratefully acknowledged. This work was supported by FAPESP, CNPq and CAPES.

\section{REFERENCES}

Andreotti, P. F., Monteiro Da Silva, J. L., Bailao, A. M., Soares, C. M., Benard, G., Soares, C. P. \& Mendes-Giannini, M. J. S. (2005). Isolation and partial characterization of a $30 \mathrm{kDa}$ adhesin from Paracoccidioides brasiliensis. Microbes Infect 7, 875-881.

Boehm, M. \& Bonifacino, J. S. (2001). Adaptins: the final recount. Mol Biol Cell 12, 2907-2920.

Brummer, E., Restrepo, A., Hanson, L. H. \& Stevens, D. A. (1990). Virulence of Paracoccidioides brasiliensis: the influence of in vitro passage and storage. Mycopathologia 109, 13-18.

Calcagno, A. M., Nino-Vega, G., San-Blas, F. \& San-Blas, G. (1998). Geographic discrimination of Paracoccidioides brasiliensis strains by randomly amplified polymorphic DNA analysis. J Clin Microbiol 36, 1733-1736.

Castaneda, E., Brummer, E., Pappagianis, D. \& Stevens, D. A. (1987). Chronic pulmonary and disseminated paracoccidioidomycosis in mice: quantitation of progression and chronicity. $J$ Med Vet Mycol 25, 377-387.

Felipe, M. S., Andrade, R. V., Petrofeza, S. S., Maranhao, A. Q., Torres, F. A., Albuquerque, P., Arraes, F. B., Arruda, M., Azevedo, M. O. \& other authors (2003). Transcriptome characterization of the dimorphic and pathogenic fungus Paracoccidioides brasiliensis by EST analysis. Yeast 20, 263-271.
Fusco Almeida, A. M., Matsumoto, M. T., Baeza, L. C., de Oliveira e Silva, R. B., Kleiner, A. A. P., Melhem, M. S. C., Mendes Giannini, M. J. S. \& the Laboratory Group on Cryptococcosis (2007). Molecular typing and antifungal susceptibility of clinical sequential isolates of Cryptococcus neoformans from Sao Paulo State, Brazil. FEMS Yeast Res 7, 152-164.

Gokool, S. (2003). $\sigma 1$ - and $\mu 1$-adaptin homologues of Leishmania mexicana are required for parasite survival in the infected host. J Biol Chem 278, 29400-29409.

Kurokawa, C. S., Lopes, C. R., Sugizaki, M. F., Kuramae, E. E., Franco, M. F. \& Peraçoli, M. T. (2005). Virulence profile of ten Paracoccidioides brasiliensis isolates: association with morphologic and genetic patterns. Rev Inst Med Trop Sao Paulo 47, 257-262.

Lasker, B. A., Page, L. S., Lott, T. J. \& Kobayashi, G. S. (1992). Isolation, characterization, and sequencing of Candida albicans repetitive element 2. Gene 116, 51-57.

Molinari-Madlum, E. E. W. I., Felipe, M. S. S. \& Soares, C. M. A. (1999). Virulence of Paracoccidoides brasiliensis isolates can be correlated to groups defined by random amplified polymorphic DNA analysis. Med Mycol 37, 269-276.

Motta, T. R., Moreira-Filho, C. A., Mendes, R. P., Souza, L. R., Sugizak, M. F., Baueb, S., Calich, V. L. \& Vaz, C. A. (2002). Evaluation of DNA polymorphisms amplified by arbitrary primers (RAPD) as genetically associated elements to differentiate virulent and nonvirulent Paracoccidioides brasiliensis isolates. FEMS Immunol Med Microbiol 33, 151-157.

Munn, A. L. (2001). Molecular requirements for the internalization step of endocytosis: insights from yeast. Biochim Biophys Acta 1535, 236-257.

Oliveira, A. A., Alves, V. S., Moreira, E. S. A., Correa, A. Jr \& Cisalpino, P. S. (2002). Genetic polymorphism of Paracoccidioides brasiliensis by PFGE and RAPD. Annu Rev Biomed Sci 4, (special issue) 5 .

Soares, C. M., Madlun, E. E., Da Silva, S. P., Pereira, M. \& Felipe, M. S. (1995). Characterization of Paracoccidioides brasiliensis isolates by random amplified polymorphic DNA analysis. J Clin Microbiol 33, 505-507.

Tan, H. \& Andrews, N. W. (2002). Don't bother to knock - the cell invasion strategy of Trypanosoma cruzi. Trends Parasitol 18, 427-428. 